\title{
INICIAÇÃO CIENTÍFICA NA EDUCAÇÃO INFANTIL: AS DIFICULDADES AO TRABALHAR PESQUISA COM OS ALUNOS DAS TURMAS DE JARDIM DE INFÂNCIA
}

\author{
SCIENTIFIC INITIATION IN CHILDHOOD EDUCATION: THE \\ DIFFICULTIES WHEN WORKING RESEARCH WITH STUDENTS \\ IN CHILDREN'S GARDEN CLASSES
}

\author{
Juliana Zinn Kochhann (julianaszinn@gmail.com) \\ Instituto Federal de Educação, Ciências e Tecnologia Sul-rio-grandense (IFSUL) \\ Lissane Dolores Ricacheski (lissanedolores@gmail.com) \\ Instituto Federal de Educação, Ciências e Tecnologia Sul-rio-grandense (IFSUL) \\ Queila Martins Henkel (martinsqueila9@gmail.com) \\ Instituto Federal de Educação, Ciências e Tecnologia Sul-rio-grandense (IFSUL)
}

Resumo: O presente estudo busca identificar as principais dificuldades das professoras de Educação Infantil em utilizar a pesquisa como metodologia de ensino. Visto que, observou-se a resistência das professoras do município de Nova Hartz em assumir a docência das turmas de jardins, visto que teriam que aplicar um projeto de pesquisa para, posteriormente, apresentar na Feira de Iniciação Científica do Município. Isto posto, trata-se de uma pesquisa qualiquantitativa, acerca de identificar os impedimentos mais relevantes para trabalhar a pesquisa em sala de aula com crianças de 4 e 5 anos. Utilizou-se como ferramenta de coleta de dados um questionário online, respondido por professoras que atuam nas 24 turmas de Jardim (níveis A e B) da Rede Municipal de Nova Hartz e para verificação dos dados a análise de conteúdo. Após os resultados analisados, constatou-se que as dificuldades mais predominantes mencionadas pelas professoras foram a falta de estrutura, recursos e materiais necessários para desenvolver a pesquisa, como também no envolvimento dos alunos no decorrer dela. Sobretudo, envolver crianças da Educação Infantil no processo de pesquisa como metodologia é instigar a curiosidade inata que elas possuem e transformá-la num sujeito protagonista no processo da construção do conhecimento.

Palavras-chave: Educação Infantil; Iniciação Científica; Pesquisa como Metodologia.

\begin{abstract}
This study seeks to identify the main difficulties of early childhood teachers in using research as a teaching methodology. Since, it was observed the resistance of teachers from the municipality of Nova Hartz to take on teaching garden classes, since they would have to apply a research project to later present at the Municipal Scientific Initiation Fair. That said, it is qualitative and quantitative research, about identifying the most relevant impediments to work with classroom research with children aged 4 and 5 years. An online questionnaire was used as a data collection tool, answered by teachers who work in the 24 classes in Jardim (levels A and B) of the Municipal Network of Nova Hartz and to verify the data in the content analysis. After the results were analyzed, it was found that the most prevalent difficulties mentioned by the teachers
\end{abstract}


were the lack of structure, resources and materials necessary to develop the research, as well as the involvement of students in the course of it. Above all, involving children in early childhood education in the research process as a methodology is to instigate their innate curiosity and transform them into a protagonist in the process of building knowledge.

Keywords: Early Childhood Education; Scientific research; Research as Methodology.

\section{INTRODUÇÃO}

A Iniciação Científica na Educação Infantil iniciou no Município de Nova Hartz no ano de 2015, decorrente de uma parceria com a Fundação Escola Técnica Liberato Salzano Vieira da Cunha, localizada em Novo Hamburgo-RS. A Instituição, juntamente com seus profissionais, realizou intervenções pedagógicas junto às escolas de Ensino Fundamental da rede municipal de Nova Hartz, explorando a metodologia científica e o processo de orientação de projetos científicos.

Para um trabalho mais efetivo em relação ao desenvolvimento do método científico, foi oportunizado aos professores um momento de formação através do curso "Projetos Científicos e Tecnológicos na Escola", sendo ministradas palestras sobre a implementação da iniciação científica na sala de aula e orientação no decorrer do desenvolvimento dos projetos científicos.

A partir disso, cada uma das escolas municipais de Nova Hartz incorporou em seu calendário letivo um período destinado à realização das feiras escolares, nos mesmos moldes de avaliação e organização da Feira Municipal. Os projetos apresentados envolvem alunos do Jardim (nível A e B) ao $9^{\circ}$ ano do Ensino Fundamental, sendo os melhores projetos inscritos na etapa municipal posteriormente. Os projetos selecionados na Feira Municipal estavam automaticamente inscritos na Mostratec Júnior, Feira de Iniciação Científica promovida pela Fundação Liberato.

Segundo relatos de uma das integrantes da equipe da SMECTEL (Secretaria Municipal de Educação, Cultura, Turismo, Esporte e Lazer) a Iniciação Científica transformou de uma forma muito positiva a prática docente dos educadores da rede de ensino do Município de Nova Hartz. No entanto, ainda há uma certa resistência de alguns, principalmente das professoras de Educação Infantil, que evitavam trabalhar com as turmas de Jardim, por serem de uma das faixas etárias a participar do projeto do município de iniciação científica. Em 2017, durante uma reunião com a SMECTEL, 
quando questionadas a respeito, as educadoras relataram dificuldades em trabalhar com a pesquisa na Educação Infantil.

Desse modo, analisando a experiência vivenciada por uma das pesquisadoras, a qual faz parte da Rede de Ensino do Município de Nova Hartz, surgiu o interesse por aprofundar esse tema, refletindo sobre o problema encontrado: Quais as principais dificuldades encontradas por professoras da Educação Infantil ao trabalhar pesquisa?

Desta forma, elencam-se algumas inquietações e/ou questionamentos, que fomentaram o interesse em realizar esta pesquisa, na qual se buscou identificar: Como é o envolvimento dos alunos da Educação Infantil no processo da pesquisa? Como é a participação da família? De que forma se dá a escolha do tema de pesquisa? A pesquisa é utilizada somente para um projeto, a fins de participação da feira da escola? A resistência de alguns professores acomodados em suas aulas tradicionais impede o uso desta metodologia de ensino?

Assim, pretende-se alcançar o objetivo principal deste artigo, que é identificar quais as principais dificuldades encontradas pelas professoras ao trabalhar com pesquisa com os alunos das turmas de jardins em Nova Hartz-RS.

Na sequência desta escrita, o segundo capítulo aborda o referencial teórico sobre a pesquisa: desafio da Professora da Educação Infantil, onde destacam-se importantes autores que abordam o assunto deste estudo; prosseguindo, o terceiro capítulo apresenta a metodologia da pesquisa, que trata detalhadamente os procedimentos metodológicos utilizados; o quarto capítulo versa sobre a apresentação e discussão dos resultados, evidenciando os dados coletados que resultam no objetivo do trabalho; e por fim, o quinto capítulo discorre sobre as considerações finais, onde são apresentados os resultados obtidos neste estudo.

\section{PESQUISA: DESAFIO DA PROFESSORA DA EDUCAÇÃO INFANTIL}

Quando se buscam formas de inovação na Educação, pensa-se logo em uso das tecnologias. Com a vida moderna, quase tudo passa a ser visto como algo fugaz. Cada dia uma novidade, um novo aplicativo, de maneira que uma notícia que hoje é novidade, amanhã passa a não ser mais. Além disso, sabemos que existem muitas realidades, nem sempre o que é lançamento em algum lugar, é novidade em outro. Assim sendo, a pesquisa na educação é um desafio para professoras e professores na Educação Infantil, Ensino Fundamental, Médio, Técnico, Superior e Pós-Graduação. 
O propósito na práxis das professoras, em especial as que atuam na Educação Infantil, é transformar a prática diária com as crianças em vivências significativas, prazerosas, instigantes, emocionantes, relevantes, que serão transformadas, em algum momento, em aprendizagens. A esse respeito Thompson (2011, p. 24)

\begin{abstract}
Atuar pedagogicamente implica um processo dialético de mediação entre o sujeito que aprende e o objeto do conhecimento. Isso nos leva a refletir sobre uma necessária prática pedagógica, oportunizadora de experiências, no sentido de favorecer o desenvolvimento da criança, por meio de estimulações que permitam à criança estabelecer associações significativas nas suas aprendizagens.
\end{abstract}

Para Silva e Braiante, o conceito da aprendizagem significativa,

[...] se fundamenta na construção de um novo conhecimento, a partir da interação não-arbitrária e não-literal com os conhecimentos prévios. Isso quer dizer que o estudante precisa do conhecimento prévio relevante dentro de sua estrutura cognitiva para dar-lhe significado, ao contrário, não poderá obter uma aprendizagem significativa. (SILVA; BRAIANTE, 2018, p. 4, 5.).

Como elaborar experiências que construam aprendizagens significativas e/ou que sirvam de conhecimento prévio para as crianças ao longo da vida? Responder este questionamento, sempre que se pensa na elaboração do planejamento, não é tarefa fácil. Para Demo (2008, p. 2), o caminho a ser trilhado pelo educador é a pesquisa, pois “educar pela pesquisa tem como condição primeira que o profissional da educação seja pesquisador, ou seja, maneje a pesquisa como princípio científico e educativo e a tenha como atitude cotidiana".

A professora da Educação Infantil nem sempre compreende o fazer pedagógico como um fazer da pesquisa, talvez porque na sua formação não tenha tido essa visão ou por não ter recebido essa informação ao longo da sua caminhada formativa. Demo (2008, p. 2), afirma que o professor não precisa ser "um pesquisador 'profissional', sobretudo na educação básica, já que não a cultiva em si, mas como um instrumento principal do processo educativo. Não se busca um 'profissional da pesquisa', mas um profissional da educação pela pesquisa” (grifos do autor).

A formação continuada dos educadores deve ser vista como um processo de aprimoramento do fazer docente, da práxis pedagógica, do ser professor, do ser pesquisador. Para Demo (2008, p. 4-6), “O que melhor distingue a educação escolar de outros tipos e espaços educativos é o fazer-se e refazer na e pela pesquisa. A própria vida como tal é um espaço naturalmente educativo, à medida que induz à aprendizagem constante $[\ldots] "$. 
Constituir-se como professora/pesquisadora é o desafio que a educadora da educação infantil precisa enfrentar, para que consiga superar as possíveis dificuldades do ofício. Compreender que a pesquisa pode ser vista como experiência lúdica pelas crianças, que são curiosas na sua essência é fundamental, uma vez que a construção dos saberes ao longo da vida começa no nascimento. Experienciamos tudo que assimilamos, que aprendemos, pesquisar é algo natural, só é preciso aprimorar as técnicas.

\section{METODOLOGIA}

\subsection{Tipo de Estudo}

O presente estudo é uma pesquisa descritiva com análise predominante qualitativa. Caracterizam-se como pesquisa descritiva os estudos que procuram investigar opiniões ou projeções futuras, por meio das respostas obtidas. Conforme Vergara (2000), a pesquisa descritiva expõe as características de determinada população ou fenômeno, estabelece correlações entre variáveis e define sua natureza.

\subsection{Participantes da pesquisa}

Esta pesquisa foi realizada com vinte e quatro professoras que atuam ou atuaram nas turmas de Jardim A (4 anos) e Jardim B (5 anos), no município de Nova Hartz - RS. A participação dos professores foi de forma voluntária e anônima, a partir da solicitação de que os mesmos respondessem a um questionário online.

\subsection{Instrumentos de obtenção de informações}

Foi utilizado como instrumentos de pesquisa um questionário online com dez questões, entre elas, cinco objetivas e cinco descritivas. Entretanto, o enfoque principal buscou ir ao encontro do objetivo desta pesquisa, sendo a questão seis primordial para o levantamento de dados: "Dentro da sua realidade docente, quais as principais dificuldades encontradas em trabalhar Pesquisa na Educação Infantil?’”

Os procedimentos de coleta de dados iniciaram com a apresentação do projeto de pesquisa às coordenadoras pedagógicas das escolas. Após o aceite, foi pedido que as mesmas enviassem o link do formulário para os professores de Jardins (nível A e B) e explicassem que a participação era anônima e voluntária, mas que era de grande relevância.

\subsection{Procedimento de Análise}

Recebido em: $01 / 09 / 2020$

Aceito em: 27/10/2020 
Utiliza-se nesse estudo a proposta de Análise de Conteúdos que, para Bardin (2009), é estabelecida em três polos: a pré-análise, que condiz com a escolha dos materiais a serem submetidos à análise; a exploração do material, quando foram coletados os dados necessários para o estudo e o tratamento dos resultados, que classificou-se e quantificou-se as categorias emergidas das respostas.

Utilizou-se, também, a análise estatística descritiva, através de frequências e percentuais.

\section{APRESENTAÇÃO E DISCUSSÃO DOS RESULTADOS}

Com o intuito de identificar quais as principais dificuldades encontradas ao trabalhar pesquisa com os alunos das turmas de jardins em Nova Hartz-RS, os relatos das 24 professoras das 8 escolas municipais foram analisados. A fim de situar o leitor, primeiramente será descrito, a partir do quadro 1 , o contexto no qual a pesquisa ocorreu. Quadro 1- Perfil dos sujeitos investigados

\begin{tabular}{|c|c|c|c|c|}
\hline Professores: & Idades: & Formação & $\begin{array}{l}\text { Tempo de } \\
\text { Trabalho }\end{array}$ & $\begin{array}{c}\text { Atividades de Pesquisa em } \\
\text { Sala de Aula: }\end{array}$ \\
\hline 1 & 28 anos & Superior Completo & 8 anos & Realiza sempre que possível \\
\hline 2 & 33 anos & Superior Completo & 10 anos & Realiza sempre que possível \\
\hline 3 & 36 anos & Pós-Graduação & 5 anos & Realiza somente para a Feira Científica \\
\hline 4 & 36 anos & Pós-Graduação & 10 anos & Realiza sempre que possível \\
\hline 5 & 38 anos & Pós-Graduação & 7 anos & Realiza sempre que possível \\
\hline 6 & 53 anos & Superior Completo & 3 anos & Não realiza pesquisa \\
\hline 7 & 26 anos & Pós-Graduação & 10 anos & Realiza sempre que possível \\
\hline 8 & 36 anos & Pós-Graduação & 8 anos & Realiza sempre que possível \\
\hline 9 & 37 anos & Pós-Graduação & 16 anos & Realiza sempre que possível \\
\hline 10 & 39 anos & Pós-Graduação & 19 anos & Realiza sempre que possível \\
\hline 11 & 26 anos & Pós-Graduação & 9 anos & Realiza somente para a Feira Científica \\
\hline 12 & 25 anos & Pós-Graduação & 8 anos & Realiza sempre que possível \\
\hline
\end{tabular}

Recebido em: $01 / 09 / 2020$

Aceito em: $27 / 10 / 2020$ 
Vol. 3, n. 3, 2020 - Edição Especial: A Pesquisa como Princípio Pedagógico

ISSN: 2595- 4520

\begin{tabular}{|c|c|c|c|c|}
\hline 13 & 59 anos & Superior Completo & 1 anos & Realiza sempre que possível \\
\hline 14 & 38 anos & Pós-Graduação & 10 anos & Realiza sempre que possível \\
\hline 15 & 25 anos & Pós-Graduação & 5 anos & Realiza sempre que possível \\
\hline 16 & 54 anos & Pós-Graduação Inc. & 5 anos & Realiza somente para a Feira Científica \\
\hline 17 & 31 anos & Pós-Graduação & 7 anos & Realiza somente para a Feira Científica \\
\hline 18 & 32 anos & Superior Completo & 13 anos & Não realiza pesquisa \\
\hline 19 & 36 anos & Superior Completo & 8 anos & Não realiza pesquisa \\
\hline 20 & 38 anos & Superior Completo & 16 anos & Realiza sempre que possível \\
\hline 21 & 34 anos & Pós-Graduação & 16 anos & Realiza sempre que possível \\
\hline 22 & 37 anos & Pós-Graduação & 10 anos & Realiza sempre que possível \\
\hline 23 & 51 anos & Pós-Graduação & 20 anos & Realiza sempre que possível \\
\hline 24 & 31 anos & Pós-Graduação & 11 anos & Realiza sempre que possível \\
\hline
\end{tabular}

Fonte: Elaborada pelas autoras durante a pesquisa.

Como visto, a faixa etária dos sujeitos participantes da pesquisa foi de 25 a 59 anos. Todas mulheres, já que na docência a prevalência do sexo feminino é comum. $\mathrm{O}$ magistério, desde o século passado, era considerado profissão feminina, tendo como um dos principais motivos alegados para isso os baixos salários oferecidos, o que, para uma sociedade machista, era desonroso e até humilhante para o homem o exercício dessa profissão. Além disso, se via na mulher a vocação materna, com isso, para muitos, elas saberiam lidar melhor com as crianças (SAFFIOTI, 1969; BARRETO, 1981). É essa realidade comum que permanece ainda nos dias atuais, principalmente na Educação Infantil, como se percebeu nesta pesquisa.

Outra resposta comum a todas foi o vínculo empregatício. No momento da coleta de dados, observou-se que todas as professoras atuantes nas turmas de jardim são efetivas no cargo de Professoras de Educação Infantil. 
Em relação à formação, 67\% das professoras participantes possuem pósgraduação. Sobre esse aspecto, Nóvoa (1995) salienta a importância da continuidade da formação ao relatar que

\begin{abstract}
A formação de professores pode desempenhar um papel importante na configuração de uma "nova" profissionalidade docente, estimulando a emergência de uma cultura profissional no seio do professorado e de uma cultura organizacional no seio das escolas (NÓVOA, 1995, p.24).
\end{abstract}

Ao serem questionadas sobre a frequência que trabalham com a pesquisa como metodologia de ensino em sala de aula, $71 \%$ das professoras relatou que utilizam pesquisa em seus planos de aula sempre que possível, já $17 \%$ usam pesquisa somente para desenvolver o projeto da turma para a Feira de Iniciação Científica que ocorre uma vez ao ano e $12 \%$ não trabalha com pesquisa em sala de aula.

Falar em pesquisa científica como metodologia para o ensino da Educação Infantil inicialmente assusta os professores que $\log$ a associam a pesquisas universitárias ou de adolescentes no Ensino Médio. Todavia, esquecemos que as crianças pesquisam desde bebês. Trata-se de um esforço -muito prazeroso- que estes fazem para estabelecer relações, compreender o mundo completamente novo que se mostra a eles, atuar sobre ele e então após algumas hipóteses conseguir agir.

Nesse sentido Reis et al, evidencia que,

[...] é necessário que o cidadão seja alfabetizado científica e tecnologicamente, de forma a promover a democratização da ciência [...]E quanto mais cedo esse processo for iniciado, mais fácil a aproximação entre os produtores e os consumidores da ciência e da tecnologia" (REIS et al, 2020, p. 207).

A educação, no contexto do educar pela pesquisa, deve ser entendida como "processo de formação da competência humana com qualidade formal e política, encontrando-se, no conhecimento inovador, a alavanca principal da intervenção da ética” (DEMO, 2008, p. 1).

Essa educação cuja proposta pedagógica é educar pela pesquisa requer que o professor e aluno manejem a pesquisa como princípio científico e educativo e a tenham como atitude cotidiana, cabendo ao professor, o papel de mediador desse processo. Como afirma Siqueira (2005, p. 21) 
o educando é o agente principal da aprendizagem. Não existe educação, aprendizagem ou instituto de ensino sem ele. $\mathrm{O}$ educador é importante como intermediário entre os conteúdos e os educandos, exercendo uma ação exterior, auxiliando, coordenando, planejando, despertando, induzindo e mostrando os caminhos e os instrumentos essenciais para sua formação cultural e profissional.

Nesse contexto, a aprendizagem é centrada no aluno, que, em parceira com o professor, constrói conhecimento. Nele, não há espaço para o docente que se limita à aula expositiva, incentiva a cópia e a transcrição de informação.

Através dos dados coletados nas 24 respostas, destacamos os desafios relatados pelas professoras para trabalhar pesquisa com alunos tão pequenos. Analisamos, a seguir, os dados referentes às principais dificuldades encontradas.

Em relação a esses fatores, os sujeitos dos estudos foram questionados sobre quais eram as principais dificuldades encontradas em trabalhar pesquisa na Educação Infantil. As respostas dos mesmos foram ordenadas em 4 categorias, apresentadas na Figura 1.

\section{Dentro da sua realidade docente, quais as principais dificuldades encontradas em trabalhar Pesquisa na Educação Infantil?}
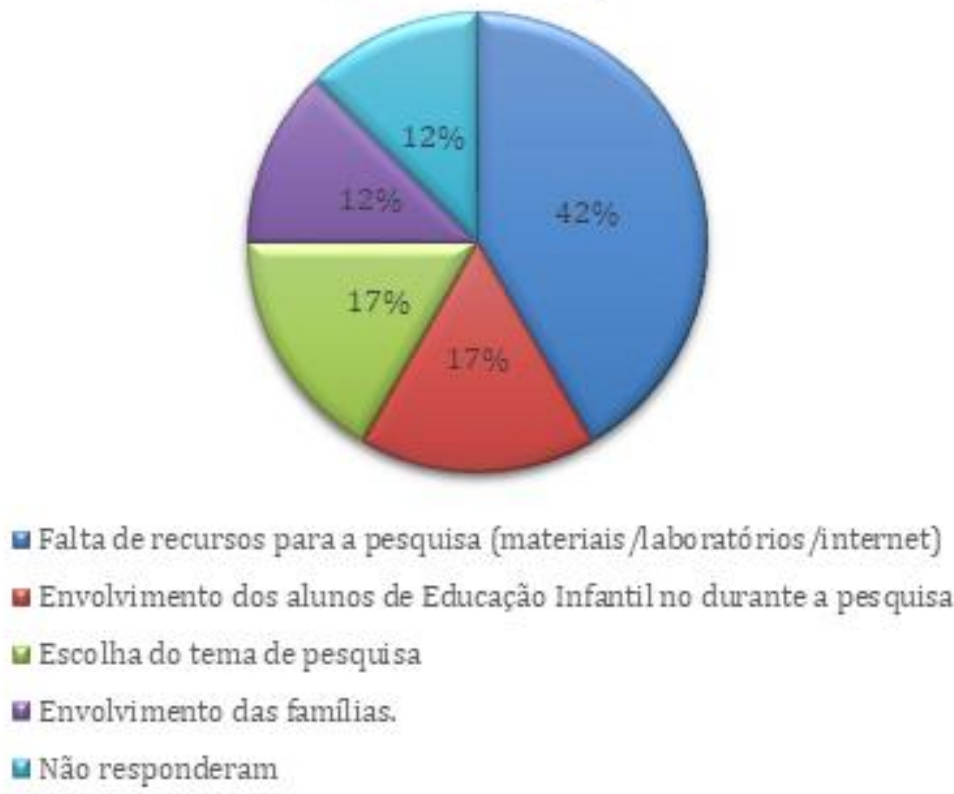

Figura 1 - Principais dificuldades encontradas em trabalhar com pesquisa na Educação Infantil

Segundo $42 \%$ das respostas, a falta de recursos para realizar pesquisa é a maior barreira encontrada pelas educadoras. Diante dessas respostas, foram referenciados a falta de materiais, de recursos financeiros, de acesso à Internet, de laboratório de informática e de espaço próprio para realizar pesquisa na instituição escolar. 
Para Demo (1996, p. 22) "Quando nada existe, deve entrar o professor como motivação ininterrupta da pesquisa, multiplicando para o aluno oportunidades de praticar a busca por materiais, que ele mesmo procura e traz". Neste sentido, o autor relata que não importa o tipo de material, que pode vir até do lixo, o importante é incentivar a criança a produzir, a criar, a indagar, pois “" $[$... o professor criativo induz o aluno a criar também, ao montar materiais que permitam ao aluno a manipular, experimentar, ver de perto, e principalmente refazer" (DEMO, 2008, p.22).

O interesse e envolvimento dos alunos da Educação Infantil em pesquisa foram descritas em 17\% das respostas; a escolha do tema da pesquisa foi citada em 17\% das respostas das professoras como dificultador para se realizar pesquisa. Segundo relatos dessas docentes, a escolha do tema a trabalhar no projeto é algo difícil, pois é através dele que as propostas vão sendo "pensadas" e isso afeta diretamente o envolvimento das crianças que na maioria das vezes "não tem interesse ou mudam de interesse rapidamente" e isso acaba atrapalhando a continuidade ao projeto. Aqui encontramos uma justificativa que envolve o cotidiano do trabalho das pesquisadas, que percebem a oscilação dos interesses das crianças. Para Barbosa e Horn (2019, p. 34), “[...] se faz necessário criar novas narrativas para situar o fazer cotidiano, contar, recontar, analisar e encantar o dia a dia, constituindo-se em um dos meios para retomar a rotina e dar a ela uma nova configuração, um novo significado".

É importante que as educadoras repensem o processo de construção do saber, do experienciar das crianças, pois

\begin{abstract}
Isso também implica criar rotinas pensadas a partir de elementos locais, contextos significativos, rotinas indeterminadas e híbridas. Ou seja, pensar as rotinas como práticas educacionais que também podem ser variáveis, múltiplas, mesmo quando recorrentes, reincidentes. Fazer um movimento de recriar, todos os dias, o que se fez até então, num movimento de fazer, desfazer, refazer e fazer novamente a partir da experiência vivida e compartilhada (BARBOSA; HORN, 2019, p. 34).
\end{abstract}

A professora precisa ser uma pesquisadora e incentivadora, para que a criança tenha interesse e adquira o prazer em pesquisar. A esse respeito, Marques (2007, p. 5), afirma que:

É por isso que o professor precisa ser um pesquisador. Precisa ser um pesquisador do pensamento do seu aluno. Precisa descobrir o que o seu aluno pensa e como pensa. Precisa descobrir quais os caminhos que levam a uma construção: da inexistência de uma capacidade para uma capacidade ativa e efetiva. 
Os assuntos (temas gerador da pesquisa) podem ser variados, dos simples aos mais complexos; podem durar pouco tempo, ou render dias; mas se não houver o olhar sensível do professor, que trabalhe a partir das curiosidades e necessidades de seus alunos, ajudando-os a compreender o sentidos para suas dúvidas, participar das construções do seu próprio conhecimento, não há pesquisa de fato, que tenha sentido para essa criança.

De acordo com as Diretrizes Curriculares Nacionais da Educação Infantil (BRASIL, 2010, p.14), a criança é definida como sujeito, que, "nas interações, relações e práticas cotidianas que vivencia, constrói sua identidade pessoal e coletiva, brinca, imagina, fantasia, deseja, aprende, observa, experimenta, narra, questiona e constrói sentidos [...]”, por isso a educadora precisa instigar a criança a realizar pesquisa desde a Educação Infantil, para que esta prática faça parte das suas vivências e seja vista como algo prazeroso, significativo.

Para $12 \%$ das professoras, a falta de envolvimento das famílias é outro fator que dificulta a pesquisa na educação infantil. Segundo TEDESCO,

Essa erosão do apoio familiar não se expressa só na falta de tempo para ajudar as crianças nos trabalhos escolares ou para acompanhar sua trajetória escolar. Num sentido mais geral e mais profundo, produziu-se uma nova dissolução entre família, pela qual as crianças chegam à escola com um núcleo básico de desenvolvimento da personalidade caracterizado seja pela debilidade dos quadros de referência que diferem dos que a escola supõe e para os quais se preparou. (2002, p.36).

Desta forma, observa-se a importância da participação da família nas propostas escolares, sendo o papel dos pais dar apoio e estimular o desenvolvimento dos seus filhos durante toda a vida escolar enquanto educando.

\section{CONSIDERAÇÕES FINAIS}

O propósito deste estudo foi verificar as principais dificuldades encontradas pelas professoras da Educação Infantil ao trabalhar a Pesquisa com seus alunos de Jardim (A e B). A partir do contexto encontrado, abrangendo vinte e quatro professoras/pedagogas de Educação Infantil das turmas de Jardim, no município de Nova Hartz, constatou-se a realidade desses profissionais em relação; ao ensino pela pesquisa em sala de aula, como método pedagógico para uma aprendizagem significativa para os alunos. 
Em relação à frequência que trabalham com a pesquisa como metodologia de ensino em sala de aula, a maior parte das docentes relatou que costuma utilizar esse método sempre que possível. No entanto, ainda há profissionais que só aderem a pesquisa por exigência do projeto científico que a turma precisa apresentar na Feira de Iniciação Científica da Escola.

Um aspecto preocupante é o de que $12 \%$ da população pesquisada não trabalha com pesquisa em sala de aula, nem mesmo quando exigido, ressaltando uma significativa resistência de alguns docentes em trabalhar com essa metodologia. Para compreender essa realidade e atingir o objetivo deste estudo, analisou-se as principais dificuldades ao trabalhar com pesquisa na Educação Infantil.

Desse modo, constatou-se a necessidade de investimento, por parte do executivo municipal, para que as escolas de educação infantil do município sejam providas de melhorias na estrutura, equipando o ambiente escolar com materiais tecnológicos e específicos para que as crianças possam experienciar e pesquisar com seus pares e educadores.

Outros dificultadores descritos nas respostas foram: a participação da família, a escolha dos temas ao trabalhar através desse método e o envolvimento dos alunos dessa faixa etária no processo de pesquisa.

Estes dificultadores não devem ser considerados empecilhos ou justificativa para não realizar pesquisa com crianças na educação infantil. É necessário refletir e pautar as ações do fazer docente, avaliando a forma como se produz o conhecimento, desde a base da educação básica: educação infantil.

Este movimento pode iniciar a partir de objetivos traçados no Projeto político Pedagógico das escolas. Por conseguinte, serão necessárias formações de preparação dos professores para que busquem novas formas de produção do conhecimento científico que instiguem a prática docente.

Sendo assim, as professoras terão como incentivar e envolver as crianças da Educação Infantil em todas as etapas do processo de criação e elaboração das pesquisas. Aproveitando a curiosidade inata que elas possuem, suas hipóteses, ao mesmo tempo precisam dar o suporte necessário para que possam ressignificar seus conhecimentos, possibilitando transmutar da condição de expectador para o de protagonista no processo da construção do conhecimento. 


\section{REFERÊNCIAS}

BARBOSA, Maria Carmen Silveira; HORN, Maria da Graça Souza. A cada dia a vida na escola com as crianças pequenas nos coloca novos desafios. In: LBUQUERQUE, Simone Santos de; FELIPE, Jane; CORSO, Luciana Vellinho. In: Para pensar à docência na educação infantil. Porto Alegre: Editora Evangraf, 2019.

BRASIL. Ministério da Educação. Secretaria de Educação Básica. Diretrizes curriculares nacionais para a educação infantil / Secretaria de Educação Básica. Brasília: MEC, SEB, 2010. In: http://ndi.ufsc.br/files/2012/02/Diretrizes-Curricularespara-a-E-I.pdf . Acesso em setembro de 2020.

DEMO, Pedro. Educar pela pesquisa. 8 edição. Campinas: Autores Associados, 2008. MARQUES, Tania Beatriz Iwaszko. Professor ou pesquisador. In: BECKER, Fernando e MARQUES, Tania Beatriz Iwaszko (orgs.). Ser professor é ser pesquisador. Porto Alegre: Mediação, 2007.

NÓVOA, A. Formação de professores e profissão docente. In: NÓVOA, A. (coord.). Os professores e sua formação. 2 ed. Lisboa: Dom Quixote, 1995.

REIS, Esterline Félix dos; TEIXEIRA, Alcinda de Souza Muniz; BOLDRINI, Bianca Maíra de Paiva Ottoni; RIZZATTI, Ivanise Maria. A importância da Feira Estadual de Ciências para a Divulgação Científica em Roraima. Revista Insignare Scientia (RIS). Vol. 3, n 2 Mai/Ago 2020. Disponível em:

https://periodicos.uffs.edu.br/index.php/RIS/article/view/11100/7477. Acesso em setembro de 2020.

SAFFIOTI, H. P. I. B. Profissionalização Feminina: Professoras Primárias e Operárias. Araraquara: F.F.C.L. de Araraquara. Mimeo, 1969.

SILVA, Jennifer Alejandra Suárez; BRAIBANTE, Mara Elisa Fortes. Aprendizagem significativa: concepções na formação inicial de professores de Ciências. Revista Insignare Scientia (RIS). Vol. 1, n. 1. Janeiro/Abril. 2018. Disponível em: https://periodicos.uffs.edu.br/index.php/RIS/article/view/7657/5132. Acesso em setembro de 2020.

SIQUEIRA, Marli Aparecida da Silva. Monografias e teses das normas técnicas ao projeto de pesquisa: teoria e prática. Brasília: Editora Consulex, 2005.

TEDESCO, J.C. O novo pacto educativo: educação, competitividade e cidadania na sociedade moderna. São Paulo: Ática, 2002.

THOMPSON, R. Neuroeducação: um novo olhar sobre a relação entre saúde e educação. In: MAIA, H. (org). Neuroeducação: a relação entre saúde e educação. Rio de Janeiro: Wak, 2011.

VERGARA, S. C. Projetos e relatórios de pesquisa em administração. São Paulo: Atlas, 2000. 
